\title{
Complex effects of fragmentation on remnant woodland plant communities of a rapidly urbanizing biodiversity hotspot
}

\author{
Cristina E. Ramalho, ${ }^{1}$ Etienne Laliberté, Pieter Poot, and Richard J. Hobbs \\ School of Plant Biology, The University of Western Australia, 35 Stirling Highway, Crawley, Perth, \\ Western Australia 6009 Australia
}

\begin{abstract}
In many cities worldwide, urbanization is leading to the rapid and extensive fragmentation of native vegetation into small and scattered urban remnants. We investigated the effects of fragmentation on plant species richness and abundance in 30 remnant Banksia woodlands in the rapidly expanding city of Perth, located in the southwestern Australian global biodiversity hotspot. We considered a comprehensive set of factors characterizing landscape fragmentation dynamics (current and historical remnant area and connectivity, time since isolation, and trajectories of landscape change), disturbance regimes (fire frequency, grazing, and intensity of human activities), and local environmental conditions (soil nutrient status and litter depth). We used generalized linear mixed models to determine the interactive effects of time since remnant isolation and remnant area on plant species richness, and structural equation models to disentangle the direct and indirect effects of landscape and local factors on plant species richness and abundance. Fragmentation impacts were most rapid in smaller remnants. Indeed, in the small remnants, native plant species richness was halved in only a few decades after isolation, suggesting an underlying rapid loss of habitat quality. We found that richness and abundance of woody species were higher in historically large remnants and lower in the rural areas, despite these rural remnants showing greater connectivity. Richness of native herbaceous species declined with time since isolation, mainly in the smaller remnants, and this was associated with altered soil properties. Furthermore, increased litter depth (possibly indicating higher productivity) and increased abundance of nonnative herbaceous species in the older and smaller remnants was associated with a decline in the abundance of native herbaceous species. Our study suggests that in rapidly expanding cities, landscape fragmentation can have major and complex effects on remnant vegetation. Yet these impacts might take several decades to manifest themselves. Hence, understanding the long-term conservation capacity of newly formed remnants, which is key to setting conservation priorities, requires consideration of landscape fragmentation and land use history. Moreover, the smaller and older remnants may already display changes due to fragmentation, providing clues for urban planning and ecosystem management that help to protect urban remnant plant diversity.
\end{abstract}

Key words: generalized linear mixed modeling; global biodiversity hotspot; land use history; landscape fragmentation; structural equation modeling; urban remnants; urbanization.

\section{INTRODUCTION}

The world is experiencing an unprecedented urban transition. Between 2000 and 2030, global urban population is expected to grow from three to five billion people, and middle-sized cities (500000 to 1 million people), in which most of the current urban expansion is occurring, are expected to triple in area (UNFPA 2007). Furthermore, the shape of the cities is changing, becoming increasingly dispersed and expansive (Seto et al. 2010). While in many cities urban expansion is taking

Manuscript received 28 June 2013; revised 14 January 2014; accepted 21 January 2014; final version received 19 February 2014. Corresponding Editor: J. J. Battles.

${ }^{1}$ Present address: Western Australian Department of Parks and Wildlife, Locked Bag 104, Bentley Delivery Centre, Western Australia 6983 Australia.

E-mail: cristina.e.ramalho@gmail.com place largely on agricultural land (Seto et al. 2000), in others it is also leading to the rapid and extensive loss of native vegetation and its fragmentation into small and isolated urban remnants (Hahs et al. 2009). As a result, urbanization is a primary cause of species endangerment (Czech et al. 2000, Burgman et al. 2007) and a threat to the conservation value of protected areas in and near metropolitan regions (Wittemyer et al. 2008). This is especially concerning in global biodiversity hotspots, which contain a large proportion of endemic species (Myers et al. 2000, Liu et al. 2003).

The effects of fragmentation in urban areas are complex and diverse and affect remnant plant communities via two main pathways. First, fragmentation reduces habitat size and thus has a direct effect on species colonization-extinction dynamics (sensu MacArthur and Wilson 1967). Rare species are most vulnerable to fragmentation because smaller remnants 


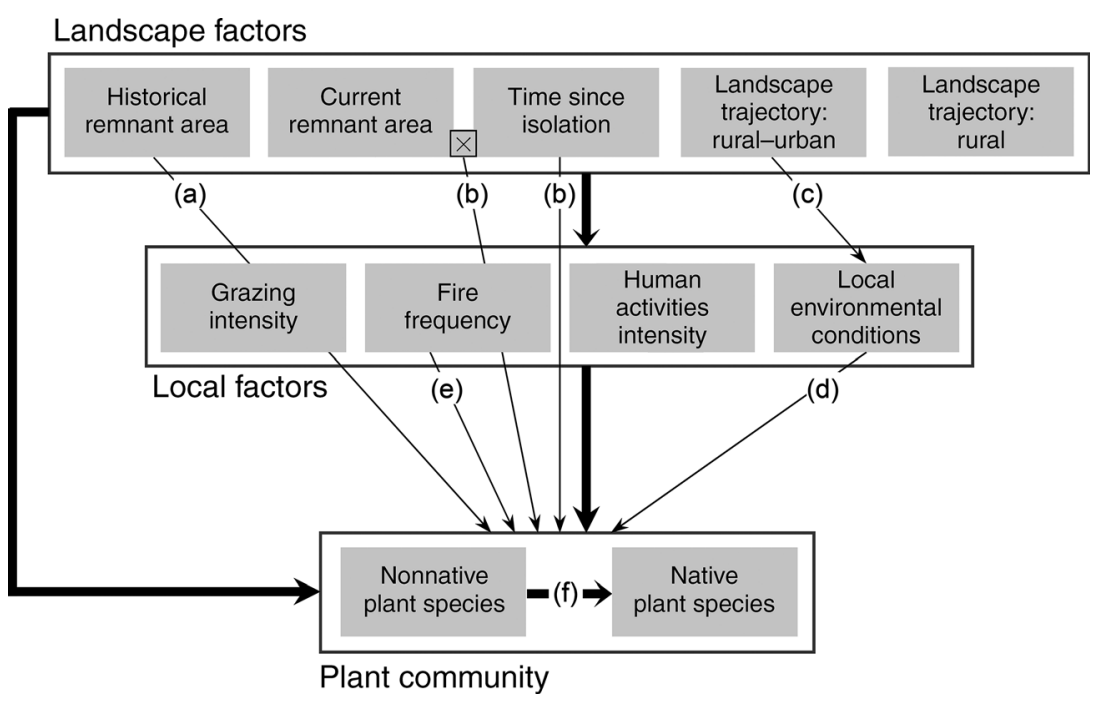

FIG. 1. Conceptual model used in the study. The boxes represent major conceptual constructs. The multiplication symbol $(\times)$ between current remnant area and time since isolation represents the interaction term between these variables. Thick arrows represent the general relationships that were examined. Narrow arrows represent the specific relationships that were hypothesized a priori (letters a-f).

support smaller population sizes, but abundant species can also be affected through impaired seed dispersal and pollination (Tilman et al. 1994, Aguilar et al. 2006). Second, fragmentation has an indirect effect on remnant vegetation via alteration of the natural (e.g., fire and grazing) and anthropogenic (e.g., trampling) disturbance regimes and local environmental conditions. Alteration of the latter can be due to edge effects, which are spillover effects from the surrounding urban matrix (Hobbs and Yates 2003).

The effects of fragmentation on remnant plant communities are not necessarily immediate. Indeed, changes to colonization-extinction dynamics can take some time to manifest themselves (Ovaskainen and Hanski 2002, Krauss et al. 2010), with some species drifting to extinction while others invade (Kuussaari et al. 2009, Vilà and Ibáñez 2011). The length of this delay depends on several factors, including species life span, remnant area, and landscape connectivity. Longer delays occur for species with longer life spans (woody species vs. herbaceous species), and for larger and more connected remnants (Kuussaari et al. 2009). The effects of fragmentation on remnant plant communities via alteration of disturbance regimes and local environmental conditions are also likely to have a cumulative impact over time. Due to the overriding influence of human activities in urban areas, those effects might have a more rapid and stronger impact than the effects of fragmentation alone on colonization-extinction dynamics (Williams et al. 2006).

Understanding of the effects of fragmentation in rapidly urbanizing landscapes has been limited for two main reasons. First, previous studies have mainly analyzed the influence of landscape and local factors individually (e.g., Hamberg et al. 2008), or more often, using aggregated urbanization measures (e.g., population density, distance to the city center) that are assumed to encapsulate the effects of fragmentation, age, and degree of urban development (McDonnell and Pickett 1990, McDonnell and Hahs 2008). Second, despite an increasing recognition of the importance of a temporal perspective (e.g., Hahs et al. 2009), previous urban ecological studies have not adequately considered the delayed nature of fragmentation impacts and the effects of land use legacies on vegetation patterns. An explicit consideration of the temporal dynamics of landscape change and the multiple landscape fragmentation effects is, however, crucial for better understanding the effects of urbanization on remnant ecosystems, as well as allowing more targeted conservation actions (Schlesinger et al. 2008, Ramalho and Hobbs 2012).

In this study, we aimed to understand the effects of fragmentation on plant species richness and abundance of 30 remnant Banksia woodlands of the Perth Metropolitan Area. We were particularly interested in understanding the effects of fragmentation on species richness, given the city's location in the southwestern Australian global biodiversity hotspot (Hopper and Gioia 2004). To do so, we followed the conceptual model presented in Fig. 1. We hypothesized that (a) species richness and abundance are better explained by historical rather than current remnant area; (b) with time since isolation, richness and abundance of native species decrease, whereas richness and abundance of nonnative species increase, and that these changes are likely to be faster in smaller than larger remnants (Helm et al. 2006, Kuussaari et al. 2009); (c) rural and urban remnants originally fragmented for agriculture have different local environmental conditions from those directly fragmented for urbanization, due to agrarian 
land use legacies (e.g., nutrient runoff and livestock grazing [Foster et al. 2003]); (d) these land use legacies lead to an increased abundance of nonnative species (Vilà and Ibáñez 2011); (e) increased fire frequency also results in an increased abundance of nonnative species (Fisher et al. 2009a); (f) increased abundance of nonnative species leads to native species displacement.

\section{Methods \\ Study area}

The study was conducted in remnant Banksia woodlands of the Perth Metropolitan Area, Western Australia $\left(31^{\circ} 57^{\prime} 18.64^{\prime \prime} \mathrm{S}, 115^{\circ} 51^{\prime} 30.37^{\prime \prime}\right.$ E; Appendix A). The study area has a flat to gently undulating topography and is situated on two ancient dune systems, the Spearwood (Middle to Late Pleistocene) and Bassendean dunes (Early Pleistocene to Late Pliocene [Kendrick et al. 1991, Laliberté et al. 2012]). These dunes are composed of well-drained and strongly weathered pale yellow (Spearwood) or white (Bassendean) quartz sands, although there are poorly drained organicmatter-rich soils surrounding the lower interdunal swamps and lakes (Kendrick et al. 1991). The coarsetextured soils ( $97 \%$ sand) are extremely poor in major plant nutrients, have low cation exchange capacity, and are acidic, typically in the $\mathrm{pH}$ range of 4.5-6.0 (McArthur et al. 2004). The climate of the region is mediterranean, with a mean annual precipitation of 740 $\mathrm{mm}, 80 \%$ of which falls in winter (between May and August) and only $4 \%$ in summer (December to February [Australian Bureau of Metereology 2011]). The study area is located in the South-West Australian Floristic Region, which is a global biodiversity hotspot with exceptionally high levels of floristic diversity, endemism, and species geographic turnover (Hopper and Gioia 2004). Banksia woodlands have an open canopy dominated by Banksia attenuata and B. menziesii, and other less-abundant tree species, including Eucalyptus marginata and Allocasuarina fraseriana. The species-rich understory is dominated by sclerophyllous shrubs from the families Proteaceae, Myrtaceae, Fabaceae, and Ericaceae, and perennial herbaceous plants from the families Restionaceae, Cyperaceae, and Haemodoraceae. Most nonnative species are herbaceous and originate from the Mediterranean Basin and South African Cape Region (Dodd and Griffin 1989).

Perth is the fastest-growing capital city in Australia (Australian Bureau of Statistics 2013), currently sprawling $>120 \mathrm{~km}$ along the coast and covering $>100000$ ha. The city is dominated by suburban development with 12 story houses at an average density of six houses per hectare (Weller 2009), and with only a few, localized industrial and high-density building areas. Perth's current population of 1900000 is estimated to reach 3 million by 2050 (Australian Bureau of Statistics 2013). The city was founded in 1829, shortly after European settlement, and urbanization has been the main driver of Banksia woodland fragmentation. Urban growth peaked from the 1960s onwards, fuelled by a mining boom that has largely driven the state's economy since then (Weller 2009). As the city expanded, the extent and configuration of remnant vegetation changed progressively as surrounding suburbs were developed in stages. Still, the urban matrix remained fairly unchanged, with the only main driver of landscape transformation being block subdivision. Banksia woodlands persist in a few large conservation and Crown Land areas on the current city boundaries, and in urban reserves (most of which are small and isolated), linear strips on roadside verges, and rural private properties. The extensive and rapid urban sprawl has had large impacts on these communities through habitat loss, introduction of nonnative species and plant diseases, and alteration of the disturbance regimes (Stenhouse 2004, Fisher et al. 2009a).

\section{Remnant selection and sampling design}

Geographic data from the Perth Metropolitan Area was assembled from different governmental agencies in an ArcGIS 9.3 database (ESRI 2008) (Appendix B). Selection of remnants, i.e., fragments of native vegetation that had not been cleared in the past for other land uses, was based on a 2006 vectorial remnant vegetation map provided by the Western Australian Department of Planning. Remnants were classified as suitable for sampling if they had an area $>1$ ha and narrowest width $>70 \mathrm{~m}$, were isolated by other land use types or by a main road, and were located within a radius of $30 \mathrm{~km}$ from the city center, on Bassendean or Spearwood soils (excluding wet and periodically waterlogged soils). Remnants selected were then classified into three size classes (1-5 ha; 5-50 ha; >50 ha), and four classes of time since urbanization (urbanized by 1965, 1985, 2006, still in a rural matrix). The classes of remnant size were defined after examination of the spatial characteristics of the remnants. The classes of time since urbanization were chosen in order to encapsulate the main landscape changes since the urban boom in the 1960s. Three remnants belonging to each size and time since urbanization class were randomly selected. From the potential sample of 36 remnants, only 30 were selected for sampling (Appendix A) because there were fewer than three remnants available in some classes. In particular, no remnants urbanized in 1965 and $>50$ ha were available. Final selection was refined and, whenever possible, remnants with the following characteristics were excluded: (a) $<500 \mathrm{~m}$ apart (to minimize spatial autocorrelation); (b) with $>30 \%$ of the area composed of wet or periodically waterlogged soils; (c) divided by minor roads or fences, when different types of land use history were evident between patches (e.g., clearing or grazing).

Three, five, and seven plots were randomly located in each remnant with 1-5 ha, 5-50 ha, and $>50$ ha, respectively $(n=130)$. Plots were composed of nested circular areas where different variables were measured. Nested circular areas included two concentric circles of 
$11 \mathrm{~m}$ and $5.5 \mathrm{~m}$ radius, plus three circles of $1.5 \mathrm{~m}$ radius located in the north, south, and randomly selected east or west $5.5 \mathrm{~m}$ circle locations (configuration of the sampling plot in Appendix C). All plots were located at least $25 \mathrm{~m}$ from the remnant margin, $5 \mathrm{~m}$ from main tracks, and had not been burnt in the previous five years.

\section{Vegetation survey}

Vegetation sampling took place in the spring and early summer (peak flowering season) of 2008 and 2009. Within each plot, all vascular plant species were recorded and their relative abundances visually estimated using 13 classes of cover $(+;<1 \% ; 1 \% ; 1-4 \% ; 5-9 \%$; $10-14 \%$; $15-19 \%$; 20-24\%; 25-34\%; 35-49\%; 50-74\%, $75-89 \%, 90-100 \%)$. Woody and herbaceous species were recorded in the $5.5 \mathrm{~m}$ and $1.5 \mathrm{~m}$ radius circles, respectively. The size of the concentric circles and the cover classes used were determined based on standard vegetation sampling procedures (Brower et al. 1997) that were adjusted to the characteristics of the plant community studied. Mean percentage cover per species per plot was calculated by taking the mean of each cover class (a value of 0.1 and 0.5 was attributed to the classes of " + " and " $<1 \%$," respectively). In the case of herbaceous species, data obtained in the three $1.5 \mathrm{~m}$ radius circles were further averaged at the plot level.

\section{Landscape and local factors}

Landscape fragmentation dynamics.-Remnant area and landscape connectivity were measured in two years, 2006 and 1965, termed as current and historical landscape configurations, respectively. Current landscape configurations were obtained using the 2006 vectorial remnant vegetation map provided by the Western Australian Department of Planning, whereas historical landscape configurations were obtained by photo-interpretation of historical aerial photographs. Seed dispersal in Banksia woodlands occurs over short distances, with most species having no specialized seed dispersal mechanism (Hopper 2009). Still, landscape connectivity could have an indirect effect through impact on pollinators and herbivores, and was estimated as the percentage cover of remnant vegetation in a $2 \mathrm{~km}$ radius buffer centered on each remnant centroid. Other related measures of landscape connectivity, such as those weighting remnant area with distance to the next remnant (Moilanen and Nieminen 2002), could not be used here because a significant part of the landscape was still continuous in 1965. Given that some remnants were progressively fragmented over the years, a set of rules was defined to determine their time since isolation (Ross et al. 2002). If a remnant was created through a single clearing event, then that event's year was considered the date of fragmentation. If a remnant was gradually reduced in size over time, through different clearing events, then the year in which the remnant was cleared to a size no greater than double the current one was considered the date of fragmentation. We used this criterion to identify the clearing event that was mostly responsible for the remnant's spatial configuration at the time of the survey. Time since remnant isolation and time since urbanization (in years) were determined through observation of aerial photos, Landsat imagery, and historical maps (Appendix B). Remnants isolated for 45 years or more were assigned an age of 45 years, given the scarcity of older records available. In this study, time since isolation was used so that the effects of fragmentation on rural remnants could also be explored. Additionally, depending on the main landscape fragmentation driver (i.e., agriculture or urbanization), remnants were classified in three classes of landscape trajectory: (1) urban remnants historically fragmented for agricultural development ("rural-urban"), (2) urban remnants directly fragmented for urban development ("woodland-urban"), and (3) remnants still located in a rural matrix ("rural"). Finally, distance to the city center was recorded for each plot, and was found to be highly correlated with landscape connectivity (Pearson's coefficient $r=0.89$ ).

Local environmental conditions.-Twenty surface soil samples $(0-10 \mathrm{~cm}$ depth) were randomly collected in the 5.5-m radius sampling circle, using a $3.5 \mathrm{~cm}$ diameter auger, bulked together at the plot level, and sent to CSBP Soil and Plant Analysis Laboratories (Perth, Australia) for soil chemical analyses [Colwell phosphorus $(\mathrm{P})$, extractable sulfur (S), Colwell potassium (K), Walkley Black percentage of organic carbon (C), nitrate $\left(\mathrm{NO}_{3}\right)$, ammonium $\left(\mathrm{NH}_{4}\right)$, and $\left.\mathrm{pH}\left(\mathrm{H}_{2} \mathrm{O}\right)\right]$. The percentage cover of bare ground and litter were visually estimated in the same area. In addition, litter layer depth (centimeters) was measured in the center and north, south, east, and west positions of the three $1.5 \mathrm{~m}$ radius sampling circles and averaged at the plot level (Appen$\operatorname{dix}$ C).

Disturbance regimes.-Fire frequency and the number of years since the last fire in the past 30 years were determined for each plot. The occurrence of wildfires, arson, and controlled burns was determined through observation of aerial photos and satellite imagery (Appendix B), as well as records from land management agencies. Despite the uncertainty associated with this method, it was the only feasible approach to determine the occurrence of most fire events in the study sites. Grazing intensity by the native western gray kangaroo (Macropus fuliginosus) and the nonnative European rabbit (Oryctolagus cuniculus), the two herbivores with the greatest impact on Banksia woodlands, was assessed within the $11 \mathrm{~m}$ radius sampling plot through a semiqualitative assessment based on Stenhouse (2005) (see Appendix D). Intensity of human activities, including trampling, waste disposal, and soil physical disturbance was estimated in a similar manner (Appendix D). Each type of disturbance was assessed using a set of criteria scored from 0 to 5 in ascending order of significance in the plot $(0=$ absent; $1=$ very low; $2=$ low; $3=$ intermediate; $4=$ high; $5=$ very high; Appendix D). 
TABLE 1. Results of the Poisson generalized linear mixed models testing the interactive effect of current remnant area and time since isolation on the woody, native, and nonnative herbaceous species richness.

\begin{tabular}{lccc}
\hline \hline \multicolumn{1}{c}{ Species richness } & Current remnant area & $\begin{array}{c}\text { Time since } \\
\text { isolation }\end{array}$ & Current remnant area $\times$ time since isolation \\
\hline Woody species & NS & NS & $0.017^{* *}$ \\
Native herbaceous species & NS & $-0.006^{*}$ & $0.013^{*}$ \\
Nonnative herbaceous species & $-0.269^{*}$ & NS & $-0.025^{*}$ \\
\hline
\end{tabular}

Note: Standardized $\beta$ and $P$ values are provided.

$* P \leq 0.05 ; * * P \leq 0.01$; NS is not significant.

Final composite variables measuring each type of disturbance were calculated by summing the different scores and dividing by the total maximum value. The landscape and local factors analyzed in the study are presented in Appendix E.

\section{Data analysis}

We performed statistical analyses separately for woody species, and native and nonnative herbaceous species, given the different life history and origin, respectively, of these groups. We used generalized linear mixed models (GLMM) with Poisson error distribution and log-link function (Zuur et al. 2009) to, first, test the interactive effect between current remnant area and time since isolation and, second, identify the landscape and local factors that better explained plant species richness. In these models, remnant was used as a random effect and landscape and local factors were used as fixed effects. In the models testing the interactive effect between remnant area and time since isolation, only these two fixed effects and their interaction term were included. Predictors were centered on their means so that coefficients could be interpreted as the amount of change in the response variable following a unit change in the predictor, holding other predictors constant at their mean values (Aiken and West 1991). Collinear variables with Pearson correlation coefficient $>0.65$ were not introduced in the same model and their effects tested separately. Model selection was based on Akaike's Information Criterion (AIC). Residuals were visually inspected to check for model assumptions (Zuur et al. 2009). Models were constructed using the lme4 package (Bates et al. 2011) in the $\mathrm{R}$ environment ( $\mathrm{R}$ Development Core Team 2011).

We then used structural equation modeling (SEM) (Grace 2006) to analyze the effect of landscape on local factors and determine their direct and indirect influence on plant species richness and abundance. The conceptual model used to guide SEM analyses is presented in Fig. 1. Selection of variables to represent the conceptual entities of interest was as follows. First, among the three classes of landscape trajectory (i.e., rural-urban, woodland-urban, rural), the class rural-urban was selected to account for possible agrarian land use legacies in the urban remnants. The class rural was highly correlated with current landscape connectivity (ANOVA, $r=0.79$; $F=47.02 ; P<0.0001)$, and the latter was used instead of the former, given its selection in the best-fitting GLMM models. Second, for local environmental conditions, the percentage of organic $\mathrm{C}$ and litter depth were selected given their selection in the best-fitting GLMM model for native species richness. Although soil $\mathrm{P}$ concentration did not have a significant effect on species richness, this variable was selected given its potential effect on the abundance of nonnative species (Fisher et al. 2009b).

We examined all direct and indirect effects of landscape on the plant community. The interaction between time since isolation and current remnant area was the only interaction between factors that was systematically tested. We used a stepwise backward procedure for model estimation, where starting from a full model we iteratively eliminated paths between variables based on the examination of the $P$ values of individual path coefficients, the standardized residual covariances, and modification indices. We also examined the chi-square statistic (a ratio less than two between the chi-square and the number of degrees of freedom indicates good fit) and $P$ value (a significant $P$ value indicates poor fit; $P<0.1$ threshold used) for evaluation of overall model fitness and model selection (Grace 2006). Despite the small sample size, the models were consistent and stable throughout the process of model estimation, and the fit between model expectations and data was acceptable. Structural equation models were run using the Amos software (Arbuckle 2010).

\section{Results}

A total of 292 plant species, including 115 woody (104 shrubs and 11 trees) and 177 herbaceous species (137 native and 40 nonnative), were recorded across the 30 remnants. There was high species turnover among remnants, with $70 \%$ of the native species only found in $\leq 20 \%$ of the sites.

The GLMMs testing the interactive effect of time since isolation and remnant area on species richness showed that richness of woody species declined with time since isolation, but only in the smaller remnants (Table 1, Fig. 2). Similarly, richness of native herbaceous species declined with time since isolation in the smaller and average-sized remnants (Table 1, Fig. 2). On the other hand, richness of nonnative herbaceous species increased with time since isolation in the smaller 

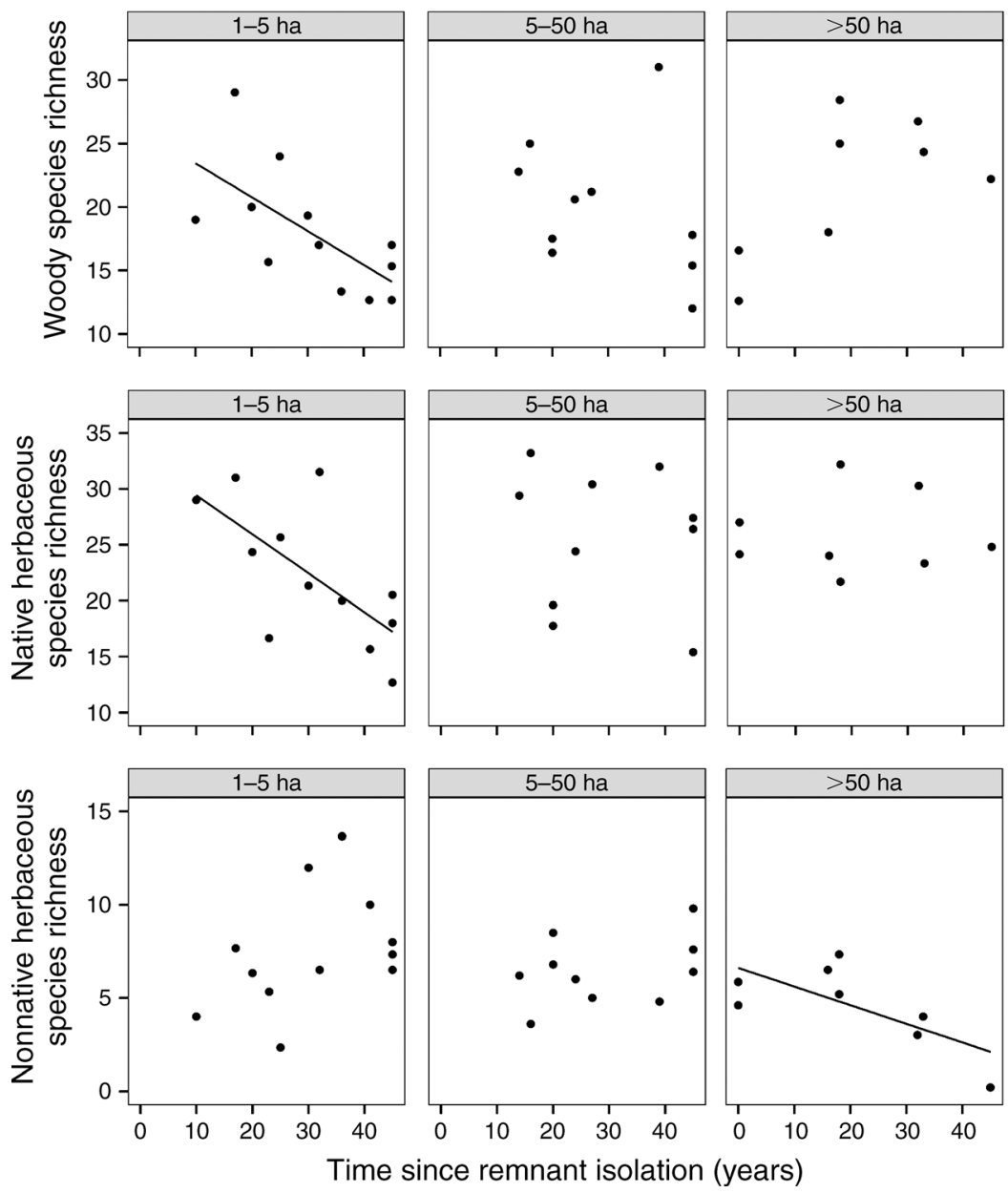

FIG. 2. Relationship between richness of (top) woody species, (middle) native herbaceous species, and (bottom) nonnative herbaceous species with time since isolation, for the three classes of remnant area considered in the study design. The solid circles represent sampled remnants, and the solid regression lines represent significant relationships $(P \leq 0.05)$.

remnants, but decreased in larger remnants (Table 1, Fig. 2).

The GLMMs testing the effect of landscape and local factors on species richness showed that richness of native woody and herbaceous species was higher in historically large remnants and lower in the more connected remnants (Table 2, Fig. 3). Furthermore, native herbaceous species richness was lower in the remnants with higher litter depth, percent organic C, and soil physical disturbance (Table 2). As observed before, richness of nonnative herbaceous species increased with time since isolation in the smaller remnants, but decreased in the larger remnants. Moreover, it was higher in less-acidic soils.

The best-fitting SEM model for the native herbaceous plant community (Fig. 4c) represented all significant paths between landscape and local factors. This model showed that human activities intensity and litter depth were higher in the older and smaller remnants. Soil P concentration was also higher in the older and smaller remnants, but only in those with lower connectivity.
Grazing intensity by native herbivores was higher in larger remnants, whereas grazing intensity by nonnative herbivores was higher in better-connected remnants. Fire frequency was lower in smaller remnants, as well as in more connected, rural remnants. The percentage of organic $\mathrm{C}$ increased with litter depth and decreased with grazing intensity by native herbivores. Fire frequency and human activities intensity were positively correlated. No significant effects of historical remnant area and landscape trajectory rural-urban on local factors were observed in the best models (Fig. 4c).

The best-fitting SEM model for the woody plant community (Fig. 4a) significantly explained the observed variation in woody plant species richness $\left(R^{2}=0.54\right)$ and abundance $\left(R^{2}=0.91\right)$. Abundance of woody species was higher in historically large remnants and lower in the more connected, rural remnants. Woody species richness was strongly positively associated with species abundance, but also increased with fire frequency. In the best-fitting model for the nonnative herbaceous community (Fig. $4 \mathrm{~b})$, species richness $\left(R^{2}=0.85\right)$ 
TABle 2. Results of the Poisson generalized linear mixed models testing the effects of landscape and local factors on the woody, native, and nonnative herbaceous species richness.

\begin{tabular}{|c|c|c|c|c|}
\hline Species & Stand. $\beta$ & SE & $z$ & $P$ \\
\hline \multicolumn{5}{|l|}{ Woody species } \\
\hline Historical remnant area & 0.173 & 0.035 & 4.950 & $<0.001$ \\
\hline Current landscape connectivity & -0.001 & 0.000 & -4.29 & $<0.001$ \\
\hline \multicolumn{5}{|l|}{ Native herbaceous species } \\
\hline Historical remnant area & 0.120 & 0.036 & 3.353 & 0.0008 \\
\hline Current landscape connectivity & -0.001 & 0.000 & -2.661 & 0.0078 \\
\hline Soil physical disturbance & -0.531 & 0.229 & -2.324 & 0.0201 \\
\hline Percent organic carbon & -0.720 & 0.288 & -2.504 & 0.0123 \\
\hline Litter depth & -0.070 & 0.033 & -2.165 & 0.0304 \\
\hline \multicolumn{5}{|l|}{ Nonnative herbaceous species } \\
\hline Current remnant area & -0.357 & 0.125 & -2.851 & 0.0043 \\
\hline Time since isolation & 0.002 & 0.005 & 0.313 & 0.7545 \\
\hline Current remnant area $\times$ time since isolation & -0.026 & 0.010 & -2.654 & 0.0079 \\
\hline $\mathrm{pH}$ & 0.612 & 0.182 & 3.356 & 0.0008 \\
\hline
\end{tabular}

was lower in the more connected rural remnants and was almost entirely determined by species abundance. Nonnative herbaceous species abundance $\left(R^{2}=0.53\right)$ increased with time since isolation in the smaller remnants but decreased in the larger remnants (cf. Table 1, Fig. 2). Furthermore, it was strongly affected by herbivory, increasing and decreasing with grazing by nonnative and native herbivores, respectively. In the best-fitting model for the native herbaceous community (Fig. 4c), species richness $\left(R^{2}=0.92\right)$ decreased with time since isolation, more strongly so in the smaller remnants (cf. Table 1, Fig. 2). Furthermore, it was lower in remnants with higher percentage of organic C. Native herbaceous species abundance $\left(R^{2}=0.63\right)$ was, however, the variable that had the strongest direct effect on native herbaceous species richness. Abundance of native herbaceous species decreased with increasing abundance of nonnative herbaceous species and, to a lesser extent, grazing intensity by native herbivores and litter depth.

\section{DisCUSSION \\ Delayed effects of fragmentation on urban remnant vegetation}

Our results suggest that the response of Banksia woodland plant communities to fragmentation are not immediately obvious and occur over several decades. Importantly, as observed in other studies (Bolger et al. 2000, Ross et al. 2002, Ferraz et al. 2003, Krauss et al. 2010, Gibson et al. 2013), fragmentation impacts manifested themselves most rapidly in smaller remnants and among herbaceous species. Indeed, the rate of local extinction in the small remnants was very high, with richness of native woody and herbaceous plants being halved 50 years after fragmentation. In the average-sized remnants, the decline in species richness was much lower and only observed in the herbaceous plant community. No discernible changes were detected in the larger remnants. Large remnants are thought to be more resilient and take longer to respond to fragmentation
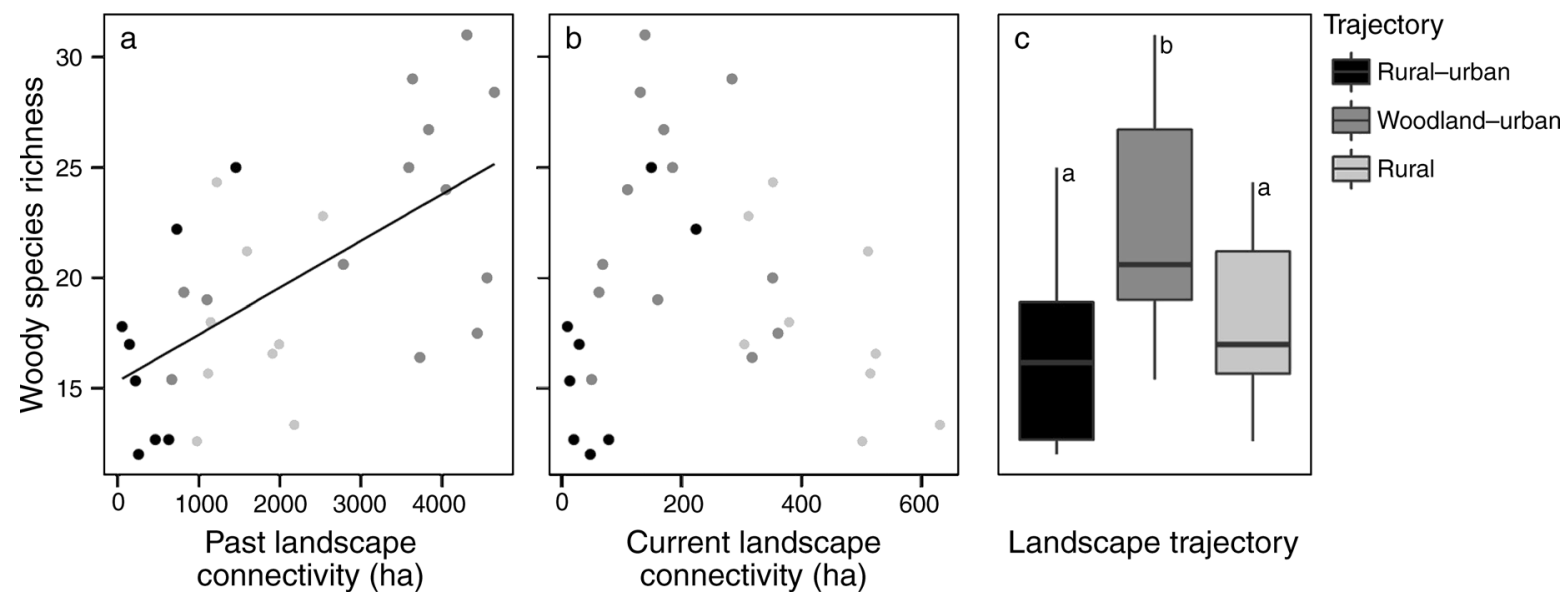

Landscape trajectory

FIG. 3. Relationship between richness of woody species and (a) historical connectivity $(r=0.62, P<0.001)$, (b) current connectivity $(r=-0.10, P=0.61)$, and (c) landscape trajectory $(P=0.023 ; 95 \% \mathrm{CI})$. Landscape trajectory is represented as: ruralurban (black), woodland-urban (dark gray), rural (light gray). 
a

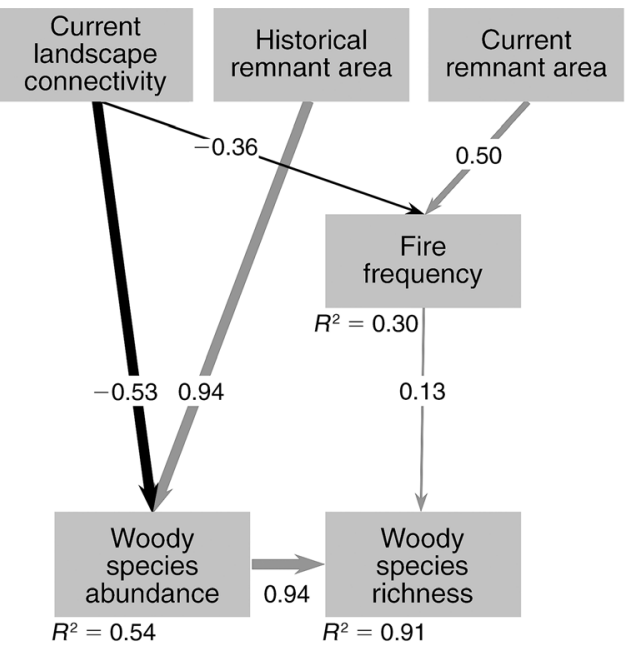

b

Current

Current
landscape

connectivity

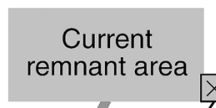

Time since isolation

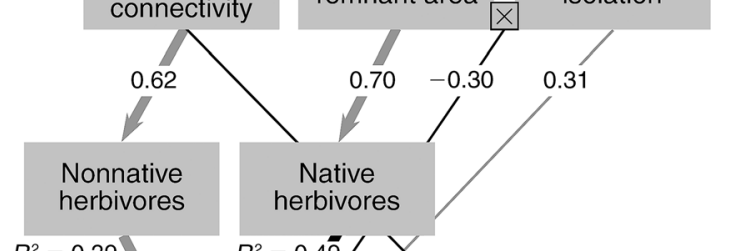

$R^{2}=0.39$

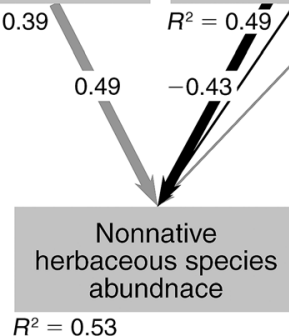

$R^{2}=0.53$

bundnace

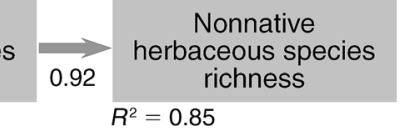

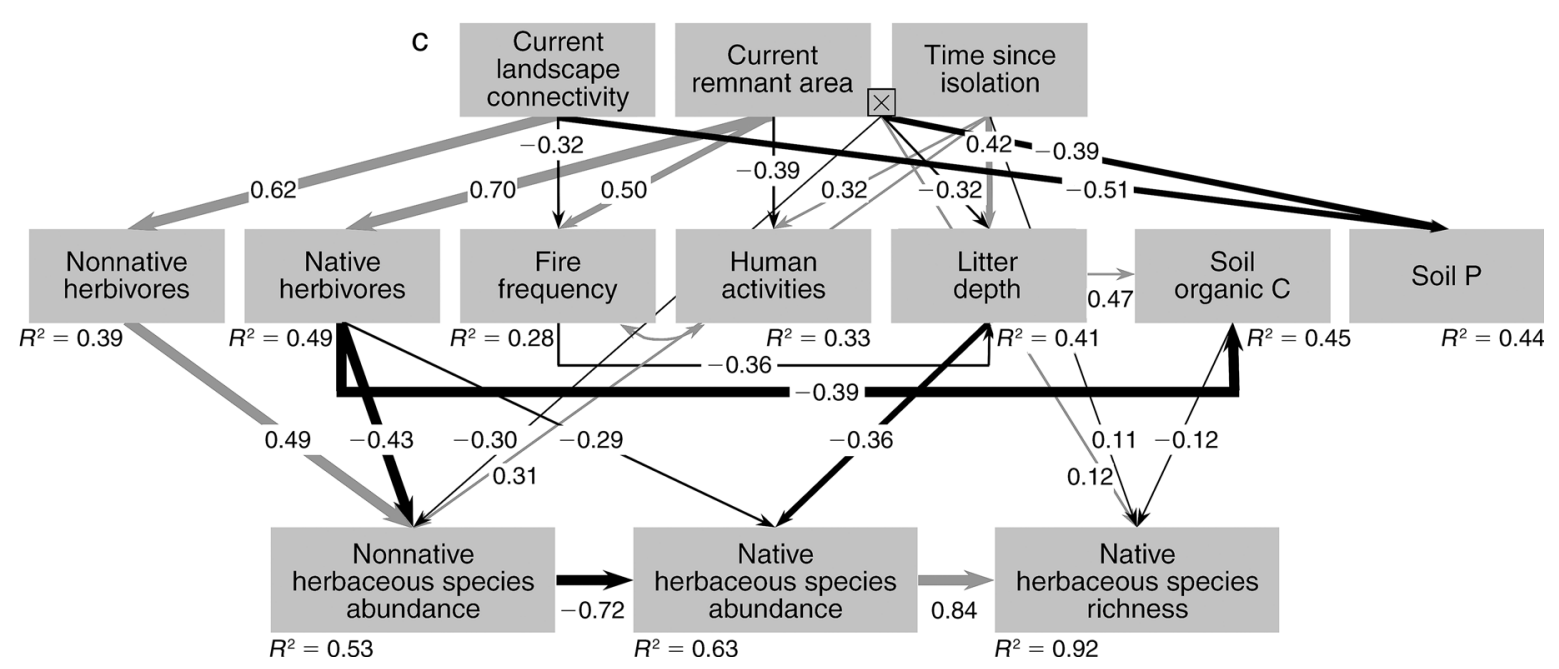

FIG. 4. Best-fitting structural equation models examining the effects of landscape and local factors on the richness and abundance of the (a) woody species $\left(\mathrm{df}=12, \chi^{2}=14.34, P=0.28\right)$, (b) nonnative herbaceous species $\left(\mathrm{df}=14, \chi^{2}=18.26, P=0.19\right)$, and (c) native herbaceous species $\left(\mathrm{df}=60, \chi^{2}=59.68, P=0.49\right)$. Straight single-headed arrows represent significant effects, whereas curved, double-headed arrows represent significant correlations. Gray arrows represent positive effects and black arrows represent negative effects. (c) All the significant paths between landscape and local factors are represented in the model. In the remaining models, only significant effects on the plant community are shown. The strength of each path is given by the arrow thickness, which is proportional to the $P$ values (wider, $P \leq 0.001$; intermediate, $P \leq 0.01$; narrower, $P \leq 0.05$ ), and the standardized coefficients.

effects (Kuussaari et al. 2009). Thus, the extent to which they will be affected by fragmentation is currently unknown and may only become apparent in time. These results, together with the fact that richness of woody species and, to a lesser extent, native herbaceous species, were better explained by past rather than current remnant area (Helm et al. 2006, Krauss et al. 2010, Sang et al. 2010), suggest a delayed response to fragmentation that is consistent with an "extinction debt" (Tilman et al. 1994, Kuussaari et al. 2009).

The observed decline in native species richness with time since isolation is likely to encapsulate the effects of fragmentation on colonization-extinction dynamics. We hypothesize that increased extinction rates (for example, due to habitat loss, and demographic and environmental stochasticity [Hanski 1998]), rather than reduced colonization, are the main driver of native species richness decline in Banksia woodlands. This is because most plant species in these environments do not have specialized seed dispersal mechanisms and generally disperse close to the mother plant (Hopper and Gioia 2004, Hopper 2009). Nevertheless, fragmentation may reduce colonization by invertebrate and vertebrate pollinators on which many plant species heavily depend in Banksia woodlands (Hopper 2009, Phillips et al. 2010).

The observed high rates of local extinction in the small remnants suggest that other extinction drivers, 
such as altered disturbance regimes and local environmental conditions, are also involved (Williams et al. 2006). Indeed, the smaller and older urban remnants were more trampled, had higher nutrient availability, and presumably higher productivity (higher soil organic $\mathrm{C}$ and litter depth). Furthermore, fire frequency and grazing by native herbivores were lower in the small remnants. These factors are likely to have a synergistic effect on the remnant plant communities, and lead to a rapid loss of habitat quality or condition, with consequent decline of native species diversity (Soga and Koike 2013). This may be predominantly linked to decreases in native species abundance, as suggested by our SEM results.

\section{Effects of landscape connectivity and land use history}

Abundance of woody species and richness of nonnative herbaceous species were lower in remnants with higher landscape connectivity, which were predominantly located in the rural areas. The higher richness of nonnative herbaceous plants in the more isolated and older remnants closer to the city center mirrors findings from other studies (Duguay et al. 2007, Gavier-Pizarro et al. 2010). These remnants have had longer exposure and proximity to the main and older networks of transport and trade, and therefore, to the main pathways of introduction, where propagule pressure is higher (Hulme 2009). The lower abundance of woody species in the more connected rural remnants is counterintuitive but may be explained by the city's development history. Large sections of rather pristine woodlands in what is today the city's middle belt (10-15 $\mathrm{km}$ from the city center) were kept undeveloped until around 20 years ago, while farther away from the city center, the landscape has been cleared and shaped by agricultural practices for a longer period. In particular, Banksia woodlands within and adjacent to rural properties were used in the past for livestock grazing (Cunningham 2005). This disturbance might have reduced the woody understory cover, leaving a legacy that is still present today, despite the fact that those practices have ceased for decades (e.g., Flinn and Vellend 2005). These results provide an example of how distance to the city center is not necessarily a good proxy of the impacts of urbanization-induced fragmentation. Cities can grow in complex and nonlinear ways (Seto et al. 2010), such that the ecological condition of one focal remnant patch may not necessarily be correlated with its position along a linear urban-to-rural transect, but instead with the characteristics of the neighboring patches, landscape fragmentation, and land use history (Ramalho and Hobbs 2012).

\section{Indirect effects of landscape fragmentation}

Fire frequency was higher in larger remnants and lower in the rural, less-populated city fringes. Despite the known positive association between fire frequency and remnant area (Ross et al. 2002) and population density (Syphard et al. 2009), fire occurrence in urban remnants is highly variable and dependent on complex factors, such as socioeconomic context, ownership, and management (Syphard et al. 2009). In the study area, for instance, remnants with higher incidence of human activities were burnt more often. Reduced fire frequency was associated with a decline in woody species richness, possibly obligate seeders, as these are not able to recruit after adult populations reach senescence (Regan et al. 2010). Although increased fire frequency is known to promote the spread of invasive plants in Banksia woodlands (e.g., Ehrharta calycina, Fisher et al. $2009 a$ ), such an effect was not observed here. This may indicate a heterogeneous fire history across the remnants in terms of other relevant fire attributes, such as fire season (Hobbs and Atkins 1990).

Grazing intensity by native and nonnative herbivores was influenced by distinct landscape factors and affected remnant vegetation in different ways. While grazing intensity by the native western gray kangaroo (Macropus fuliginosus) was mostly associated with larger remnants, grazing by the nonnative European rabbit (Oryctolagus cuniculus) was higher in the more connected rural remnants. Native and nonnative herbivores had opposing effects on nonnative herbaceous species abundance, a phenomenon that has been described before (Parker et al. 2006). Indeed, native herbivores suppressed nonnative herbaceous species abundance, as they preferably consume nonnative rather than native plant species, a mechanism that reduces invasion success and that is explained by the biotic resistance hypothesis (Levine et al. 2004). In contrast, nonnative herbivores promoted nonnative herbaceous species abundance, perhaps not by reducing the abundance of native species, as Parker et al. (2006) suggested, but by disturbing the top soil through their digging habits. Disturbance of this thin layer in the ancient and impoverished soils of the south-western Australia is known to promote invasion (Hopper 2009), as it provides an opportunity for establishment by nonnative species, which are abundant in the topsoil seed bank, and germinate and grow faster than native species (Fisher et al. 2009b).

The older and smaller remnants were more disturbed by human activities and had altered local environmental conditions, including higher litter depth, and in the more urbanized areas, higher soil $\mathrm{P}$ concentration. Contrary to other studies (e.g., Hamberg et al. 2008), anthropogenic disturbances, including trampling, did not significantly affect the plant community. This may be because of the way we assessed such disturbances or because these disturbances are still largely restricted to edge environments, which were excluded in the sampling design. The observed increased litter depth may result from changes in the remnants canopy composition, possibly due to a complex set of factors, including increased ecosystem productivity and decreased fire frequency (Ramalho 2012). Increased litter depth alters 
the understory microenvironment, increasing the percentage of soil organic $\mathrm{C}$ and shade, with consequent negative effects on the richness and abundance of native herbaceous plants (Facelli and Pickett 1991). Finally, the higher soil $\mathrm{P}$ concentration in the older and more urbanized remnants might result from a variety of urbanization-related causes, including runoff from surrounding paved and fertilized areas, and atmospheric deposition (Kaye et al. 2006, Park et al. 2010). Nevertheless, even these remnants had a relatively low soil $\mathrm{P}$ concentration $(2.75 \mathrm{mg} / \mathrm{kg}$ of Colwell $\mathrm{P})$, which might explain the absence of an expected positive correlation between soil $\mathrm{P}$ concentration and the abundance of nonnative plants (Fisher et al. 2009b). A confounding factor that might also explain the absence of this correlation is the fact that most of the older urban remnants are public parks. In these public parks, the abundance of nonnative species is likely to be partially controlled by weed management practices, which are variable across the reserves and generally absent in rural remnants.

\section{Implications for land use planning and ecosystem management}

Our study demonstrates that in a city that is rapidly expanding into native vegetation, native plant diversity in urban remnants does not necessarily reflect their current landscape context, but the historical environmental conditions present prior to urbanization. Hence, a snapshot of present biodiversity might provide a misleading picture of the remnants long-term conservation capacity (Vellend and Kharouba 2013). Although this is an obvious implication of the extinction debt concept (Kuussaari et al. 2009) and thus familiar to most ecologists, it is often unrecognized in current urban environmental policies and planning strategies. Indeed, these environmental policies and planning strategies often assess and prioritize conservation assets in a static manner, based on current or historical patterns of biodiversity distribution (e.g., regional unpublished planning documents). Hence, understanding the conservation capacity of remnant ecosystems in rapidly expanding cities requires not only the assessment of their current biodiversity, but also landscape fragmentation and land use history (Soga and Koike 2013). Most importantly, this information could be used to set conservation priorities. In particular, remnants in intact condition, recently fragmented, and/or without significant land use legacies, could be prioritized for conservation and management interventions that help in reducing fragmentation effects (Ramalho and Hobbs 2012, Soga and Koike 2013).

Our study also suggests the existence of a remnant size below which habitat quality rapidly declines, leading to a significant loss of plant diversity within a few decades after fragmentation. Although remnants that have been recently fragmented to small sizes often have large extinction debts that are rapidly paid over time
(Kuussaari et al. 2009), it is likely that the local extinction observed is exacerbated by the synergistic effect of multiple urbanization-related factors, and which lead to loss of habitat quality (Soga and Koike 2013). For the Banksia woodlands studied here, our results suggest that remnants smaller than 5-10 ha are highly vulnerable to fragmentation effects (as also suggested by Williams [2011] in the same study area). From a practical perspective, this implies that land use planners should use that area (10 ha) as a bare minimum patch size to set aside for conservation when vegetation is cleared. Also, improving habitat quality of small urban remnants may be the most effective way to retain their conservation capacity (Soga and Koike 2013).

Finally, our study suggests that grazing by native herbivores may provide biotic resistance to plant invasion in urban remnant ecosystems. Given that plant invasion control often requires substantial and continuous financial resources, it would seem worthwhile to utilize that "biotic resistance service" in ecosystem management. For that to be possible, the herbivore habitat requirements, including remnant area and landscape connectivity, necessary for the maintenance of viable populations, need to be considered at the urban planning level.

\section{Implications for urban ecological research}

Our study has several implications for urban ecological research. First, it highlights the importance of considering the temporal dynamics of landscape change in ecological studies set in rapidly urbanizing regions. Urban landscapes have often been perceived as static, and the concept of delayed responses to fragmentation has seldom been considered effectively. This can affect the study design (e.g., remnants with different fragmentation histories are grouped in the same urbanization class) and ultimately lead to misleading results (Ramalho and Hobbs 2012). Second, our study demonstrates the utility of a hierarchical modeling approach to disentangle complex, direct and indirect, effects of fragmentation on biodiversity (Grace 2006, McMahon and Diez 2007). While the assumption that fragmentation alters disturbance regimes and local environmental conditions is relatively well embedded in the foundation of landscape fragmentation research (e.g., Hobbs and Yates 2003), it is often missing in case studies quantifying the effects of landscape and/or local factors on biodiversity (Didham et al. 2012). Third, the study provides a concrete example of the complexity of urban landscapes and of how distance to the city center is not necessarily a good proxy of the degree of urbanization, the remnants fragmentation age, or ecological condition. While the urban-to-rural gradient (McDonnell and Pickett 1990) may continue to provide a useful framework for urban ecology, it is becoming clear that a more comprehensive and contextual analysis of the different landscape and local factors involved is required to understand the effects of urbanization remnant 
vegetation (McDonnell and Hahs 2008, Ramalho and Hobbs 2012).

Finally, our study suggests the cities' fragmentation histories and environmental settings should be considered in comparative studies, as they are likely to have a major influence on the variability of the biodiversity responses to urbanization across multiple cities. In cities with a young development history and expanding into relatively intact native vegetation (e.g., Perth, Cape Town, Los Angeles), fragmentation-related processes are likely to have a major influence on remnant biodiversity. Fragmentation effects may still be largely hidden in the form of extinction debts and only with time will increase the extinction rates (Hahs et al. 2009). In contrast, in cities with a long human occupation and expanding into semi-natural habitats (e.g., European cities), major extinctions may already have happened in the past (Hahs et al. 2009), and current remnant biodiversity may be largely shaped by historical land uses and land-management practices (Grove and Rackham 2001).

The cities' environmental settings can also dictate major differences in the biodiversity responses to urbanization. In the Perth Banksia woodlands, seed dispersal might not be overly affected by landscape fragmentation, because most species show limited dispersal capacity, a trait hypothesized to be related to the fact that Perth is set in one of the oldest and most climatic-buffered landscapes on earth (Hopper 2009). However, a different response to fragmentation can be expected in cities set in younger and post-glacial landscapes (e.g., most of the Northern Hemisphere), and where plant species generally have higher dispersal capacity due to an evolutionary history marked by major climatic variations (e.g., Knapp et al. 2008). Also, in resource-limited regions, urbanization-mediated subsidies can lead to major changes in productivity and stress-related factors within the remnants (e.g., water and nutrients availability [Martin and Stabler 2002]), with cascading effects on food webs (Faeth et al. 2005). However, in regions where resources are not limiting, those impacts are not necessarily expected (Faeth et al. 2005). In a study conducted in nine metropolitan areas in the United States, the responses of stream macroinvertebrates to urbanization were easily detected when the cities' environmental settings were considered, but not discernible when those were ignored (Cuffney et al. 2010). In conclusion, for a comprehensive picture of the effects of urbanization on remnant biodiversity to emerge, comparative studies should consider the cities' landscape fragmentation and land use histories, and environmental settings.

\section{ACKNOWLEDGMENTS}

We thank Paul Liebich, Juan Garibello, Graham Zemunik, and Sutomo, for their assistance in the fieldwork, Phil Ladd and Browen Keighery for their help on plant species identification, and Viki Cramer for her advice in the early stages of the project. We also thank two anonymous reviewers for their comments.
The study was funded by the School of Plant Biology, University of Western Australia (UWA). During the writing of this manuscript, C. E. Ramalho was funded by a Portuguese National Science Foundation (Fundação para a Ciência e a Tecnologia) doctoral scholarship. E. Laliberté was supported by UWA and ARC Research Fellowships (DE120100352) and R. J. Hobbs by an ARC Australian Laureate Fellowship.

Literature Cited

Aguilar, R., L. Ashworth, L. Galetto, and M. A. Aizen. 2006. Plant reproductive susceptibility to habitat fragmentation: review and synthesis through a meta-analysis. Ecology Letters 9:968-980.

Aiken, L. S., and S. G. West. 1991. Multiple regression: testing and interpreting interactions. Sage, Thousand Oaks, California, USA.

Arbuckle, J. L. 2010. Amos 19.0.0. In A. D. Corporation, editor. A. D. Corporation, Meadville, Pennsylvania, USA.

Australian Bureau of Meteorology. 2011. Climate statistics for Australian locations: monthly climate statistics. Australian Bureau of Meteorology, Melbourne, Australia.

Australian Bureau of Statistics. 2013. 3218.0-Regional Population Growth, Australia, 2011-12. Australian Bureau of Statistics, Canberra, Australia.

Bates, D., M. Maechler, and B. Bolker. 2011. Linear mixedeffects models using S4 classes. University of Wisconsin, Madison, Wisconsin, USA.

Bolger, D. T., A. V. Suarez, K. R. Crooks, S. A. Morrison, and T. J. Case. 2000. Arthropods in urban habitat fragments in southern California: area, age, and edge effects. Ecological Applications 10:1230-1248.

Brower, J. E., J. H. Zar, and C. N. von Ende. 1997. Field and laboratory methods for general ecology. Fourth edition. WCB/McGraw-Hill, Boston, Massachusetts, USA.

Burgman, M. A., D. Keith, S. D. Hopper, D. Widyatmoko, and C. Drilla. 2007. Threat syndromes and conservation of the Australian flora. Biological Conservation 134:73-82.

Cuffney, T. F., R. A. Brightbill, J. T. May, and I. R. Waite. 2010. Responses of benthic macroinvertebrates to environmental changes associated with urbanization in nine metropolitan areas. Ecological Applications 20:1384-1401.

Cunningham, I. 2005. The land of flowers: an Australian environment on the brink. Otford Press, Brighton-Le-Sands, New South Wales, Australia.

Czech, B., P. Krausman, and P. Devers. 2000. Economic associations among causes of species endangerment in the United States. BioScience 50:593-601.

Didham, R. K., V. Kapos, and R. M. Ewers. 2012. Rethinking the conceptual foundations of habitat fragmentation research. Oikos 121:161-170.

Dodd, J., and E. A. Griffin. 1989. Floristics of the Banksia woodlands. Journal of the Royal Society of Western Australia 71:89-90.

Duguay, S., F. Eigenbrod, and L. Fahrig. 2007. Effects of surrounding urbanization on non-native flora in small forest patches. Landscape Ecology 22:589-599.

ESRI. 2008. ArcGIS 9.3. ESRI, Redlands, California, USA.

Facelli, J., and S. Pickett. 1991. Plant litter: its dynamics and effects on plant community structure. Botanical Review 57:132.

Faeth, S. H., P. S. Warren, E. Shochat, and W. A. Marussich. 2005. Trophic dynamics in urban communities. BioScience 55:399-407.

Ferraz, G., G. J. Russell, P. C. Stouffer, R. O. Bierregaard, S. L. Pimm, and T. E. Lovejoy. 2003. Rates of species loss from Amazonian forest fragments. Proceedings of the National Academy of Sciences USA 100:14069-14073.

Fisher, J. L., W. A. Loneragan, K. Dixon, J. Delaney, and E. J. Veneklaas. 2009a. Altered vegetation structure and composition linked to fire frequency and plant invasion in a 
biodiverse woodland. Biological Conservation 142:22702281.

Fisher, J. L., W. A. Loneragan, K. Dixon, and E. J. Veneklaas. 2009b. Soil seed bank compositional change constrains biodiversity in an invaded species-rich woodland. Biological Conservation 142:256-269.

Flinn, K. M., and M. Vellend. 2005. Recovery of forest plant communities in post-agricultural landscapes. Frontiers in Ecology and the Environment 3:243-250.

Foster, D., F. Swanson, J. Aber, I. Burke, N. Brokaw, D. Tilman, and A. Knapp. 2003. The importance of land-use legacies to ecology and conservation. BioScience 53:77-88.

Gavier-Pizarro, G. I., V. C. Radeloff, S. I. Stewart, C. D. Huebner, and N. S. Keuler. 2010. Housing is positively associated with invasive exotic plant species richness in New England, USA. Ecological Applications 20:1913-1925.

Gibson, L., A. J. Lynam, C. J. A. Bradshaw, F. He, D. P. Bickford, D. S. Woodruff, S. Bumrungsri, and W. F. Laurance. 2013. Near-complete extinction of native small mammal fauna 25 years after forest fragmentation. Science $341: 1508-1510$

Grace, J. B. 2006. Structural equation modeling and natural systems. Cambridge University Press, Cambridge, UK.

Grove, A. T., and O. Rackham. 2001. The nature of Mediterranean Europe-an ecological history. Yale University Press, New Haven, Connecticut, USA.

Hahs, A. K., et al. 2009. A global synthesis of plant extinction rates in urban areas. Ecology Letters 12:1165-1173.

Hamberg, L., S. Lehvävirta, M. Malmivaara-Lämsä, H. Rita, and D. J. Kotze. 2008. The effects of habitat edges and trampling on understorey vegetation in urban forests in Helsinki, Finland. Applied Vegetation Science 11:83-98.

Hanski, I. 1998. Metapopulation dynamics. Nature 396:41-49.

Helm, A., I. Hanski, and M. Partel. 2006. Slow response of plant species richness to habitat loss and fragmentation. Ecology Letters 9:72-77.

Hobbs, R., and L. Atkins. 1990. Fire-related dynamics of a Banksia woodland in south-western Australia. Australian Journal of Botany 38:97-110.

Hobbs, R. J., and C. J. Yates. 2003. Impacts of ecosystem fragmentation on plant populations: generalising the idiosyncratic. Australian Journal of Botany 51:471-488.

Hopper, S. 2009. OCBIL theory: towards an integrated understanding of the evolution, ecology and conservation of biodiversity on old, climatically buffered, infertile landscapes. Plant and Soil 322:49-86.

Hopper, S. D., and P. Gioia. 2004. The Southwest Australian Floristic Region: conservation of a global hotspot of biodiversity. Annual Review of Ecology and Systematics 35:623-650.

Hulme, P. E. 2009. Trade, transport and trouble: managing invasive species pathways in an era of globalization. Journal of Applied Ecology 46:10-18.

Kaye, J. P., P. M. Groffman, N. B. Grimm, L. A. Baker, and R. V. Pouyat. 2006. A distinct urban biogeochemistry? Trends in Ecology and Evolution 21:192-199.

Kendrick, G. W., K.-H. Wyrwoll, and B. J. Szabo. 1991. Pliocene-Pleistocene coastal events and history along the western margin of Australia. Quaternary Science Reviews 10: 419-439.

Knapp, S., I. Kühn, R. Wittig, W. A. Ozinga, P. Poschlod, and S. Klotz. 2008. Urbanization causes shifts in species' trait state frequencies. Preslia 80:375-388.

Krauss, J., et al. 2010. Habitat fragmentation causes immediate and time delayed biodiversity loss at different trophic levels. Ecology Letters 13:597-605.

Kuussaari, M., et al. 2009. Extinction debt: a challenge for biodiversity conservation. Trends in Ecology and Evolution 24:564-571.

Laliberté, E., B. L. Turner, T. Costes, S. J. Pearse, K.-H. Wyrwoll, G. Zemunik, and H. Lambers. 2012. Experimental assessment of nutrient limitation along a 2-million-year dune chronosequence in the south-western Australia biodiversity hotspot. Journal of Ecology 100:631-642.

Levine, J. M., P. B. Adler, and S. G. Yelenik. 2004. A metaanalysis of biotic resistance to exotic plant invasions. Ecology Letters 7:975-989.

Liu, J., G. C. Daily, P. R. Ehrlich, and G. W. Luck. 2003. Effects of household dynamics on resource consumption and biodiversity. Nature 421:530-533.

MacArthur, R. H., and E. O. Wilson. 1967. The theory of island biogeography. Princeton University Press, Princeton, New Jersey, USA.

Martin, C. A., and L. B. Stabler. 2002. Plant gas exchange and water status in urban desert landscapes. Journal of Arid Environments 51:235-254.

McArthur, W. M., D. A. W. Johnston, L. J. Snell, Western Australia Department of Agriculture, and Australian Society of Soil Science. 2004. Reference soils of south-western Australia. Department of Agriculture, Western Australia on behalf of the Australian Society of Soil Science, Perth, Australia.

McDonnell, M. J., and A. K. Hahs. 2008. The use of gradient analysis studies in advancing our understanding of the ecology of urbanizing landscapes: current status and future directions. Landscape Ecology 23:1143-1155.

McDonnell, M. J., and S. T. A. Pickett. 1990. Ecosystem structure and function along urban-rural gradients: an unexploited opportunity for ecology. Ecology 71:1232-1237.

McMahon, S. M., and J. M. Diez. 2007. Scales of association: hierarchical linear models and the measurement of ecological systems. Ecology Letters 10:437-452.

Moilanen, A., and M. Nieminen. 2002. Simple connectivity measures in spatial ecology. Ecology 83:1131-1145.

Myers, N., R. A. Mittermeier, C. G. Mittermeier, G. A. B. Fonseca, and J. Kent. 2000. Biodiversity hotspots for conservation priorities. Nature 403:803-808.

Ovaskainen, O., and I. Hanski. 2002. Transient dynamics in metapopulation response to perturbation. Theoretical Population Biology 61:285-295.

Park, S.-J., Z. Cheng, H. Yang, E. Morris, M. Sutherland, B. McSpadden Gardener, and P. Grewal. 2010. Differences in soil chemical properties with distance to roads and age of development in urban areas. Urban Ecosystems 13:483-497.

Parker, J. D., D. E. Burkepile, and M. E. Hay. 2006. Opposing effects of native and exotic herbivores on plant invasions. Science 311:1459-1461.

Phillips, R. D., S. D. Hopper, and K. W. Dixon. 2010. Pollination ecology and the possible impacts of environmental change in the Southwest Australian Biodiversity Hotspot. Philosophical Transactions of the Royal Society B 365:517528.

R Development Core Team. 2011. R: A language and environment for statistical computing. R Foundation for Statistical Computing, Vienna, Austria.

Ramalho, C. E. 2012. Effects of urbanization on remnant woodlands. Dissertation. University of Western Australia, Perth, Australia.

Ramalho, C. E., and R. J. Hobbs. 2012. Time for a change: dynamic urban ecology. Trends in Ecology and Evolution 27: 179-188.

Regan, H., J. Crookston, R. Swab, J. Franklin, and D. Lawson. 2010. Habitat fragmentation and altered fire regime create trade-offs for an obligate seeding shrub. Ecology 91:11141123 .

Ross, K. A., B. J. Fox, and M. D. Fox. 2002. Changes to plant species richness in forest fragments: fragment age, disturbance and fire history may be as important as area. Journal of Biogeography 29:749-765.

Sang, A., T. Teder, A. Helm, and M. Pärtel. 2010. Indirect evidence for an extinction debt of grassland butterflies half 
century after habitat loss. Biological Conservation 143:14051413.

Schlesinger, M. D., P. N. Manley, and M. Holyoak. 2008. Distinguishing stressors acting on land bird communities in an urbanizing environment. Ecology 89:2302-2314.

Seto, K. C., R. K. Kaufmann, and C. E. Woodcock. 2000. Landsat reveals China's farmland reserves, but they're vanishing fast. Nature 406:121.

Seto, K. C., R. Sánchez-Rodríguez, and M. Fragkias. 2010. The new geography of contemporary urbanization and the environment. Annual Review of Environment and Resources $35: 167-194$

Soga, M., and S. Koike. 2013. Mapping the potential extinction debt of butterflies in a modern city: implications for conservation priorities in urban landscapes. Animal Conservation 16:1-11.

Stenhouse, R. N. 2004. Fragmentation and internal disturbance of native vegetation reserves in the Perth metropolitan area, Western Australia. Landscape and Urban Planning 68:389401.

Stenhouse, R. N. 2005. Assessing disturbance and vegetation condition in urban bushlands. Australian Journal of Environmental Management 12:16-26.

Syphard, A. D., V. C. Radeloff, T. J. Hawbaker, and S. I. Stewart. 2009. Conservation threats due to human-caused increases in fire frequency in Mediterranean-climate ecosystems. Conservation Biology 23:758-769.
Tilman, D., R. May, C. Lehman, and M. Nowak. 1994. Habitat destruction and the extinction debt. Nature 371:65-66.

UNFPA. 2007. State of the world population 2007. Unleashing the potential of urban growth. United Nations Population Fund, New York, New York, USA.

Vellend, M., and H. M. Kharouba. 2013. Setting conservation priorities when what you see is not what you get. Animal Conservation 16:14-15.

Vilà, M., and I. Ibáñez. 2011. Plant invasions in the landscape. Landscape Ecology 26:461-472.

Weller, R. 2009. Boomtown 2050: scenarios for a rapidly growing city. UWA Publishing, Perth, Australia.

Williams, M. 2011. Habitat resources, remnant vegetation condition and area determine distribution patterns and abundance of butterflies and day-flying moths in a fragmented urban landscape, south-west Western Australia. Journal of Insect Conservation 15:37-54.

Williams, N., J. Morgan, M. McCarthy, and M. McDonnell. 2006. Local extinction of grassland plants: the landscape matrix is more important than patch attributes. Ecology 87 : 3000-3006.

Wittemyer, G., P. Elsen, W. T. Bean, A. C. O. Burton, and J. S. Brashares. 2008. Accelerated human population growth at protected area edges. Science 321:123-126.

Zuur, A. F., E. N. Ieno, N. J. Walker, A. A. Saveliev, and G. M. Smith. 2009. Mixed effects models and extensions in ecology with R. Springer, New York, New York, USA.

\section{Supplemental Material}

\section{Appendix A}

Map of the study area and description of the 30 remnant Banksia woodlands sampled in the Perth Metropolitan Area, Australia (Ecological Archives E095-218-A1).

\section{Appendix B}

GIS data collected for the study (Ecological Archives E095-218-A2).

Appendix C

Configuration of the sampling plot (Ecological Archives E095-218-A3).

\section{Appendix D}

Description of the semi-qualitative disturbance assessment used to quantify intensity of human activities and grazing in the study remnants (Ecological Archives E095-218-A4).

\section{Appendix E}

Description of the landscape and local factors used in the study (Ecological Archives E095-218-A5). 